\title{
Medievalista
}

Online

18 | 2015

Número 18

\section{Aproximaciones historiográficas a la violencia en la Edad Media}

Cecilia Devia

\section{(2) OpenEdition}

1 Journals

Edición electrónica

URL: http://journals.openedition.org/medievalista/1109

DOI: 10.4000/medievalista.1109

ISSN: 1646-740X

Editor

Instituto de Estudos Medievais - FCSH-UNL

Referencia electrónica

Cecilia Devia, « Aproximaciones historiográficas a la violencia en la Edad Media », Medievalista [En línea], 18 | 2015, Publicado el 01 junio 2015, consultado el 10 diciembre 2020. URL : http:// journals.openedition.org/medievalista/1109; DOI : https://doi.org/10.4000/medievalista.1109

Mediavalista está licenciado com uma Licença Creative Commons - Atribuição-NãoComercial 4.0 Internacional 
Título: Aproximaciones historiográficas a la violencia en la Edad Media

Autor(es): Cecilia Devia

Universidade: Universidad de Buenos Aires

Faculdade e Departamento / Unidade de Investigação: Facultad de Filosofía y Letras,

Instituto de Historia Antigua y Medieval

Código Postal: 1002

Cidade: Ciudad Autónoma de Buenos Aires

País: Argentina

Contacto: cecidevia@yahoo.com.ar; cecidevia@gmail.com

Fonte: Medievalista [Em linha]. Dir. José Mattoso. Lisboa: IEM.

Disponível em:

http://www2.fcsh.unl.pt/iem/medievalista/MEDIEVALISTA18/devia1806.html

ISSN: 1646-740X

Data recepção do artigo: 2 de Novembro de 2014

Data aceitação do artigo: 27 de Fevereiro de 2015

\section{Resumo}

Este trabajo consiste en un breve estado de la cuestión sobre el tema de la violencia en la Edad Media, encuadrado en las siguientes coordenadas de tiempo y espacio: el Occidente europeo bajomedieval. Se tienen en cuenta en esta oportunidad exclusivamente aproximaciones de carácter historiográfico.

Primero se presentan dos momentos que se destacan en relación a la violencia en la Edad Media, enfocados principalmente desde los autores cuyas investigaciones han dejado mayor huella, para luego comentar una selección de los aportes historiográficos que se consideran más significativos publicados a lo largo de los últimos veinte años, aproximadamente.

Palavras-chave: Baja Edad Media, historiografía, Occidente europeo, violencia. 


\section{Abstract}

This paper consists of a brief state of the question on the issue of violence in the Middle Ages, framed in the following coordinates of time and space: the late medieval Western Europe. In this opportunity, it takes into account only historiographical approaches.

In the first place, are presented two moments that stand out in relation to violence in the Middle Ages, focusing mainly from the authors whose research has left more traces. Then, it discusses a selection of the most significant historiographical contributions published over the last twenty years or so.

Keywords: Historiography, Late Middle Ages, Western Europe, Violence. 


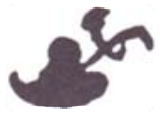

\section{Aproximaciones historiográficas a la violencia en la Edad Media}

\section{Cecilia Devia}

\section{Introducción}

Se elaborará en este trabajo un breve estado de la cuestión sobre el tema de la violencia en la Edad Media. En razón de la amplitud del asunto en cuestión, se lo acotará marcando, en líneas generales, las siguientes coordenadas de tiempo y espacio: el Occidente europeo bajomedieval. Si bien se considera que un tema tan complejo como el de la violencia requiere un abordaje multidisciplinario y aportaciones de carácter teórico, dada la brevedad de la presente contribución no se le dará en esta oportunidad ese tratamiento ${ }^{1}$. Tampoco se abordará la violencia entre Estados o proto-Estados, cuya mayor expresión es la guerra en sus diversas y variadas manifestaciones, en virtud de que se considera que es un tema que, por su magnitud, extendería excesivamente esta presentación.

Se comenzará por presentar dos momentos que se destacan en relación a la violencia en la Edad Media, enfocados principalmente desde los autores cuyas investigaciones han dejado mayor huella, para luego comentar una selección de los aportes historiográficos publicados a lo largo de los últimos veinte años, aproximadamente.

\footnotetext{
${ }^{1} \mathrm{Al}$ respecto, remito a la Primera Parte de mi tesis doctoral: DEVIA, Cecilia - Violencia y dominación en la Baja Edad Media castellana. Buenos Aires: Facultad de Filosofía y Letras (UBA), 2014 http://www.filo.uba.ar/contenidos/investigacion/institutos/historiaantiguaymedieval/libros.htm
}

Medievalista online № 18| Julho - Dezembro 2015 ( ) IEM - Instituto de Estudos Medievais 3 www2.fcsh.unl.pt/iem/medievalista 


\section{Función transicional de la violência}

Ilustrando lo que se podría denominar la función transicional de la violencia -entendida aquí como la perspectiva de historiadores, en su mayoría marxistas, que trabajan sobre la violencia como generadora de un nuevo sistema- se presentarán dos posturas que han marcado pautas en la historiografía del feudalismo, referidas a distintos momentos históricos. No se entrará en profundidad en los debates que suscitaron, ya que la intención sólo es presentar el tratamiento que ambas han dado al tema de la violencia. Los autores que se citarán manejan un criterio derivado del materialismo histórico por el cual las contradicciones de tipo estructural no se suprimen sino que se despliegan, dando lugar a dinámicas transicionales.

La primera interpretación está básicamente encarnada en Pierre Bonnassie, cuya hipótesis de trabajo se intentará resumir a continuación. A partir del estudio de las estructuras sociales, políticas y económicas de Cataluña en los siglos $\mathrm{X}_{\text {y } \mathrm{XI}^{2}}$, el autor elabora lo que posteriormente se conocerá como la tesis mutacionista ${ }^{3}$, que postula la existencia de un cambio abrupto de normas y costumbres luego de la denominada “crisis” o “revolución” del año mil.

Bonnassie sostiene que los reinos romano-germánicos que se forman a partir del siglo $\mathrm{V}$ se organizan sobre la base de las estructuras del Imperio Romano. Los poderes públicos siguen existiendo, siendo los condes sus representantes. La sociedad se dividiría básicamente en dos clases: el esclavo y el propietario libre, que está sujeto a tributo fiscal. El surgimiento del sistema feudal se daría a partir de una mutación sufrida entre fines del siglo X y principios del XI, la “mutación del año mil”, debida a la aparición de una contradicción entre el desarrollo de las fuerzas productivas -impulsado por la pequeña propiedad campesina- y las relaciones sociales en cierta medida públicas o estatales, que no pueden contenerlas. Se multiplican así una cantidad de poderes

\footnotetext{
${ }^{2}$ BONNASSIE, Pierre - Cataluña mil años atrás (siglos X-XI). Barcelona: Península, 1978.

${ }^{3}$ Que posteriormente extenderá a otras regiones europeas, con pequeños cambios en la cronología. Ver también BONNASSIE, Pierre - "Del Ródano a Galicia: génesis y modalidades del régimen feudal”. in PASTOR, Reyna (ed.) - Estructuras feudales y feudalismo en el mundo mediterráneo (siglos X-XI). Barcelona: Crítica, 1984, pp. 21-65.
}

Medievalista online № 18| Julho - Dezembro 2015 ๑ IEM - Instituto de Estudos Medievais 4 www2.fcsh.unl.pt/iem/medievalista 
políticos privados menores, ejercidos por diversos señores feudales, que desintegran la autoridad pública ejercida hasta ese momento por el conde.

Esta mutación se presenta dentro de lo que Bonnassie denomina "la espiral de violencia” ${ }^{4}$. El autor sostiene que hasta principios del siglo XI, la paz interna pudo mantenerse en toda Cataluña, debido a que los condes se veían fortalecidos por el apoyo de la Iglesia e incluso del campesinado. Además, la aristocracia, que era poco numerosa, percibía el peligro del conflicto interno frente a la latente amenaza musulmana. Pero a partir del año mil, "la sangre empieza a correr”. Bajo el efecto de las nuevas fuerzas productivas, y ante posibilidades inusitadas de crecimiento económico, las estructuras comienzan a tambalearse. "La crisis -indica el autor- nace de este hiato entre una economía transformada y unas estructuras sociales, judiciales y políticas que datan de muchos siglos”5. Mientras que en otras partes de Europa este proceso de degradación de la autoridad pública sería paulatino, en Cataluña tomaría el aspecto de una revolución, transformándose radicalmente las estructuras de la sociedad en el lapso de una generación. Lo que está en juego en todas partes, indica Bonnassie, es el aumento de riqueza que aporta el crecimiento económico: por un lado, el oro proveniente del comercio con el Islam; por otro lado, y con mayor peso, las nuevas rentas que produce la expansión agrícola ${ }^{6}$.

En este punto, aparece la reacción de la Iglesia ante el avance violento de la aristocracia, que se cristaliza en los movimientos conocidos como "la paz de Dios" y "la tregua de Dios”7. Bonnassie les supone origen y bases populares, e indica que ante la impotencia de quienes deberían asumir la instauración y mantenimiento del orden público, la Iglesia se ve obligada a tomar momentáneamente, y sin ser su deseo, el lugar de aquellos. Se pone así al frente de este movimiento pacifista, neutralizándolo y despojándolo de sus

\footnotetext{
${ }^{4}$ BONNASSIE, Pierre - Cataluña mil años atrás (siglos X-XI). Barcelona: Península, 1978, p. 237.

${ }^{5}$ BONNASSIE, Pierre - Cataluña mil años atrás (siglos $X$-XI). Barcelona: Península, 1978, p. 237.

${ }^{6}$ BONNASSIE, Pierre - Cataluña mil años atrás (siglos X-XI). Barcelona: Península, 1978, p. 258.

${ }^{7}$ Sobre la paz y tregua de Dios hay gran profusión de textos, entre ellos y a modo de ejemplo: BARTHÉLEMY, Dominique - El año mil y la Paz de Dios. La Iglesia y la sociedad feudal. Granada: Universidad de Granada-Universitat de València, 2005; BARTHÉLEMY, Dominique - Caballeros y milagros. Violencia y sacralidad en la sociedad feudal. Granada: Universitat de València, Universidad de Granada, 2006; DUBY, Georges - Los tres órdenes o lo imaginario del feudalismo. Barcelona: Argot, 1983; FLORI, Jean - Caballeros y caballería en la Edad Media. Barcelona: Paidós, 2001; IOGNAPRAT, Dominique - Ordonner et exclure. Cluny et la societé chrétienne face àl' herésie, au judaïsme et à l’ islam. 1000-1150. París: Aubier, 1998.
}

Medievalista online $N^{\circ} 18 \mid$ Julho - Dezembro 2015 ๑ IEM - Instituto de Estudos Medievais 5 www2.fcsh.unl.pt/iem/medievalista 
posibles efectos revolucionarios. Por un lado, la Iglesia debe defender ese orden que considera providencial y, por consiguiente, inmutable; por otro, no puede enfrentarse totalmente a los miembros laicos de su propia clase social. Así, indica Bonnassie, “... a condición de no tocar las posesiones eclesiásticas, la opresión castellana podrá llevarse a cabo sin obstáculos”.

Bonnassie sostiene que la idea de imponer a los combatientes y agitadores una tregua semanal nació en Cataluña, más precisamente en el sínodo de Toluges, Rosellón, en 1027, y se fue extendiendo al calor de las violencias señoriales que la habían hecho surgir. Posteriormente, se inscribe dentro de un movimiento mayor, el de la paz de Dios. Las primeras asambleas de paz se celebran sin la presencia de representantes de la autoridad civil, pero a partir de mediados del siglo XI los propios condes de Barcelona las convocan, transformándose la paz de Dios en la paz del conde.

Sobre la violencia en la transición del feudalismo al capitalismo, se presentará brevemente la interpretación del historiador marxista británico Rodney Hilton, quien considera a la lucha de clases - centrada en este momento histórico en el conflicto señor/campesino- como motor de la sociedad medieval ${ }^{9}$, de lo que puede inferirse la presencia de la violencia en su función constructora.

Hilton presenta también la dificultad, experimentada incluso por figuras marcadamente revolucionarias, para escapar de la ideología construida y mantenida por el grupo dominante, que indicaba “... que el orden social, dispuesto por la divinidad, consistía en unos grupos o estamentos que se apoyaban mutuamente, cuyas funciones eran necesarias para la estabilidad de este mundo como trampolín para el próximo”"10. Es decir, la que se conoce como ideología de los tres órdenes. Pero agrega que esta propaganda llevada adelante especialmente por el clero, a veces se volvía en contra de los dominadores. Cuando la obligación de los bellatores de proteger y defender al resto de la sociedad no se cumple -acá Hilton da el ejemplo de Francia en los siglos XIV y

\footnotetext{
${ }^{8}$ BONNASSIE, Pierre - Cataluña mil años atrás (siglos X-XI). Barcelona: Península, 1978, p. 310.

${ }^{9}$ HILTON, Rodney - “Campesinos medievales: ¿Alguna enseñanza?”. in HILTON, Rodney - Conflicto de clases y crisis del feudalismo. Barcelona: Crítica, 1988, pp. 11-24.

${ }^{10}$ HILTON, Rodney - “Campesinos medievales: ¿Alguna enseñanza?”. in HILTON, Rodney - Conflicto de clases y crisis del feudalismo. Barcelona: Crítica, 1988, pp. 11-24.
}

Medievalista online № 18| Julho - Dezembro 2015 ๑ IEM - Instituto de Estudos Medievais 6 www2.fcsh.unl.pt/iem/medievalista 
$\mathrm{XV}$ - el tercer orden, integrado por los laboratores, siente que el tan preciado orden es quebrado por los grupos dirigentes, lo que aumenta su hostilidad hacia ellos ${ }^{11}$.

En su valioso estudio sobre el movimiento campesino inglés de 1381, Hilton define a estos movimientos como “... la acción común en pos de objetivos concretos de los campesinos en cuanto clase"12. Para examinarlos tiene en cuenta tanto los factores de cambio como los de estabilidad $^{13}$, y considera como principio clave del período el respeto a la costumbre, tanto de parte de los dominados como de los dominadores ${ }^{14}$. Para el historiador inglés son los campesinos, en mayor medida que los señores, los que sostienen este punto. Así, lo que es percibido por ellos como una innovación de parte de los señores, serviría de justificativo para abandonar su papel claramente subalterno en la jerarquía social ${ }^{15}$. De ahí la contradicción que se produce en momentos de tensión: al no poder “aceptar la renuncia a los papeles tradicionales asignados a los diversos estamentos de la sociedad (cuya estructura ellos no rechazaban, al menos en principio)” -que según Hilton “parece ser siempre el factor más importante” que precipita los acontecimientos $^{16}$ - se produce el abandono de su posición en la escala social, con el objetivo de restablecer el orden de origen divino.

Al respecto, en otro pasaje de su obra Hilton hace referencia a las teorías medievales sobre el orden social. Sostiene que son realistas al reconocer la existencia de la estratificación social, y al no ocultar la presencia de una clase dominante que controla los medios de coerción y depende del trabajo de las clases gobernadas, en especial de la campesina. Reconocen también la existencia clave de un grupo de intermediarios entre Dios y el hombre, los sacerdotes. Pero Hilton considera que son teorías poco realistas porque no tienen en cuenta ningún tipo de movilidad social, con el consecuente rechazo

\footnotetext{
${ }^{11}$ Es lo mismo que hemos identificado en la rebelión irmandiña de 1467-1469. Ver DEVIA, Cecilia - La violencia en la Edad Media: la rebelión irmandiña. Vigo: Editorial Academia del Hispanismo, 2009, pp. 34-35 y 95.

12 HILTON, Rodney - Siervos liberados. Los movimientos campesinos medievales y el levantamiento inglés de 1381. Madrid: Siglo XXI, 1985, p. 77.

${ }^{13}$ HILTON, Rodney - Siervos liberados. Los movimientos campesinos medievales y el levantamiento inglés de 1381. Madrid: Siglo XXI, 1985, pp. 80-81.

${ }^{14}$ HILTON, Rodney - Siervos liberados. Los movimientos campesinos medievales y el levantamiento inglés de 1381. Madrid: Siglo XXI, 1985, pp. 86-87.

${ }^{15}$ HILTON, Rodney - Siervos liberados. Los movimientos campesinos medievales y el levantamiento inglés de 1381. Madrid: Siglo XXI, 1985, pp. 149-150.

16 HILTON, Rodney - Siervos liberados. Los movimientos campesinos medievales y el levantamiento inglés de 1381. Madrid: Siglo XXI, 1985, p. 155.
}

Medievalista online № 18| Julho - Dezembro 2015 ๑ IEM - Instituto de Estudos Medievais 7 www2.fcsh.unl.pt/iem/medievalista 
a la aparición de nuevos grupos sociales surgidos ante la creciente complejidad de la actividad económica ${ }^{17}$.

Para comprender a fondo este momento histórico, hay que tener en cuenta, entre otros elementos de peso, el aumento de la recaudación de la renta en metálico por sobre la renta en especie, que lleva a los campesinos a vender su producto en el mercado, y la formación de la industria rural a domicilio, que tiene su origen en Inglaterra e involucra a actores tanto del sector dominante como del dominado, en papeles diferentes e innovadores respecto a los tradicionales ${ }^{18}$.

Para Hilton, el rasgo distintivo de los movimientos campesinos de la Baja Edad Media es su mayor alcance, en relación con los anteriores. Esto se debe, en parte, al crecimiento de la organización estatal y el autor lo relaciona también con cambios de índole religiosa, que encarnan en dos modelos diferentes: las corrientes heréticas y los diversos tipos de cruzadas $^{19}$.

Al exponer su metodología de estudio, Hilton destaca tres puntos a investigar: la cuestión de los orígenes sociales e intelectuales de los cabecillas de los movimientos, la composición social de las masas participantes y la dilucidación de las ideas que guían a los diferentes elementos implicados ${ }^{20}$.

Hilton sostiene que, "A pesar de las marcadas diferencias entre estos movimientos campesinos de la Baja Edad Media, todos ellos tienen en común un rasgo destacado: la aparición de una conciencia de clase entre algunos de los participantes”. Pero la califica

${ }^{17}$ HILTON, Rodney - Siervos liberados. Los movimientos campesinos medievales y el levantamiento inglés de 1381. Madrid: Siglo XXI, 1985, pp. 309-310.

18 Para el caso de Castilla ver especialmente: IRADIEL MURUGARREN, Francisco Paulino “Estructuras agrarias y modelos de organización industrial precapitalista en Castilla”. in Studia Historia. Historia Medieval. 1 (1983), pp. 87-112; IRADIEL MURUGARREN, Francisco Paulino - Evolución de la industria textil castellana en los siglos XIII-XVI. Salamanca: Universidad de Salamanca, 1974; ASTARITA, Carlos - Del feudalismo al capitalismo. Cambio social y político en Castilla y Europa Occidental, 1250-1520. Granada: Universitat de Valencia-Universidad de Granada, 2005, pp. 144-72.

${ }^{19}$ HILTON, Rodney - Siervos liberados. Los movimientos campesinos medievales y el levantamiento inglés de 1381. Madrid: Siglo XXI, 1985, pp. 124-125.

${ }^{20}$ HILTON, Rodney - Siervos liberados. Los movimientos campesinos medievales y el levantamiento inglés de 1381. Madrid: Siglo XXI, 1985, p. 147.

Medievalista online № 18| Julho - Dezembro 2015 ๑ IEM - Instituto de Estudos Medievais 8 www2.fcsh.unl.pt/iem/medievalista 
como “... una conciencia de clase negativa, pues la definición que daban de clase era la de sus enemigos y no la suya propia”21.

Esta aseveración tal vez entre en contradicción con la importancia que Hilton le otorga siguiendo a la mayoría de los cronistas del levantamiento de 1381- a la petición de libertad, “... que fue la que con mayor insistencia presentaron los rebeldes en las negociaciones directas con el rey y sus consejeros”. En uno de los momentos de mayor tensión, luego de conocida la muerte del principal líder, Wat Tyler, y una vez desencadenada la represión, los rebeldes de Essex se conjuran para conservar la nueva libertad obtenida o morir combatiendo. Envían emisarios al rey solicitando “... una libertad igual a la de sus señores”, la cual, por supuesto, no le es concedida, ya que, como indica Hilton, esto “... habría supuesto un cataclismo social de incalculables consecuencias” y “... el fin de la jurisdicción señorial”, al desaparecer para siempre las bases materiales sobre las que se asentaba el sistema. Como el mismo historiador sostiene, "La petición de libertad [...] formaba parte de una petición más amplia para poner fin al régimen señorial”22.

Hilton concluye indicando que su análisis de los movimientos campesinos parece justificar su hipótesis de que las relaciones sociales rurales durante la Edad Media se caracterizan más por la conflictividad que por la armonía entre los intereses de señores y campesinos. El respeto hacia la costumbre, si bien en ocasiones modera u oculta el conflicto, no llega a eliminarlo ${ }^{23}$.

\footnotetext{
${ }^{21}$ HILTON, Rodney - Siervos liberados. Los movimientos campesinos medievales y el levantamiento inglés de 1381. Madrid: Siglo XXI, 1985, p. 171. Hilton y la escuela de historiadores marxistas ingleses plantean que la conciencia de clase es un elemento específico del sistema capitalista y que se obtiene por experimentación de la situación que vive la clase explotada. Para una visión crítica y alternativa sobre este problema, ver ASTARITA, Carlos - “¿Tuvo conciencia de clase el campesino medieval?”. in Edad Media. Revista de Historia. 3 (2000), pp. 89-113; ASTARITA, Carlos - Del feudalismo al capitalismo. Cambio social y político en Castilla y Europa Occidental, 1250-1520. Granada: Universitat de ValenciaUniversidad de Granada, 2005, pp. 173-198; ASTARITA, Carlos - "La historia de la transición del feudalismo al capitalismo en el marxismo occidental”. in Anales de Historia Antigua, Medieval y Moderna. 41 (2009), pp. 101-131.

${ }^{22}$ HILTON, Rodney - Siervos liberados. Los movimientos campesinos medievales y el levantamiento inglés de 1381. Madrid: Siglo XXI, 1985, pp. 296-298.

${ }^{23}$ HILTON, Rodney - Siervos liberados. Los movimientos campesinos medievales y el levantamiento inglés de 1381. Madrid: Siglo XXI, 1985, pp. 310-313.
}

Medievalista online № 18| Julho - Dezembro 2015 ๑ IEM - Instituto de Estudos Medievais 9 www2.fcsh.unl.pt/iem/medievalista 
Para el período de transición del feudalismo al capitalismo, que se conoce también como primera crisis del feudalismo, se puede agregar el trabajo de Salustiano Moreta sobre los malhechores feudales ${ }^{24}$. El autor los describe como

\begin{abstract}
... todos aquellos individuos que, pertenecientes a la clase feudal dominante en la formación económica-social de Castilla en los siglos XIII y XIV, emplearon la fuerza y la violencia en sus múltiples expresiones - desde el asesinato a las simples amenazas y coacciones, la violación, el robo, las correrías de expolio y rapiña, etc.- en contra de las demás clases e instituciones sociales, incluidos los miembros de la propia clase, como práctica habitual y no de las menos relevantes, para realizar determinados intereses individuales o globales de clase y, sobre todo, como reacción ante la primera gran crisis del feudalismo ${ }^{25}$.
\end{abstract}

Moreta se ocupa de destacar las notas esenciales de su definición: la vinculación del malhechor-feudal con una clase social específica, la nobleza; el ejercicio de una práctica sistemática de la violencia contra las personas -que considera inherente al feudalismo-; la violencia como una de las principales formas de reproducción de la clase dominante y como método de imposición de hegemonía sobre los dominados; la violencia como materialización de la reacción señorial ante las manifestaciones de la crisis del orden feudal.

Lo que está detrás tanto del modelo de surgimiento del feudalismo elaborado por Bonnassie y del presentado por Hilton y Moreta sobre la transición al capitalismo y sobre la violencia en relación a la crisis bajomedieval, es el problema hobbesiano del poder, que postula la necesidad del Estado para absorber la violencia, como única forma de relación posible entre sociedad y violencia. La violencia es consustancial al feudalismo, por lo que sostenemos que no hubo períodos de inusitada violencia que interrumpieran la reproducción de la sociedad, sino que ésta continuó construyéndose a través de la violencia ${ }^{26}$.

24 MORETA, Salustiano - Malhechores-feudales. Violencia, antagonismos y alianzas de clases en Castilla, siglos XIII-XIV. Madrid: Cátedra, 1978.

25 MORETA, Salustiano - Malhechores-feudales. Violencia, antagonismos y alianzas de clases en Castilla, siglos XIII-XIV. Madrid: Cátedra, 1978, p. 20.

${ }^{26}$ Ver, por ejemplo: ASTARITA, Carlos - "Prácticas del conde y formación del feudalismo. Siglos VII a XI”. in Revista de Historia Medieval. 14 (2003-2006), pp. 21-52; GAUVARD, Claude - “Conclusion”. in Le règlement des conflits au Moyen Age. Actes du XXXIè Congrès de la SHMESP (Angers, 2000). Paris: Publications de la Sorbonne, 2001, pp. 369-391. 


\section{Aportes historiográficos recientes}

En cuanto a los aportes más recientes, dado que la producción historiográfica medievalista sobre la violencia resulta prácticamente inabarcable -y más aún en estas pocas páginas- se presentará una acotada selección de las propuestas que se han considerado más valiosas, con plena conciencia de que quedará afuera gran cantidad de contribuciones, incluso muchas de las que han sido oportunamente relevadas y que revisten indudable interés.

Al solo efecto de lograr una presentación más ordenada, este estado de la cuestión se dividirá en cuatro apartados que incluyen diferentes problemas y enfoques relacionados con la violencia en la Edad Media.

\section{1 Violencia y dominación}

Entre los medievalistas en lengua francesa, se destacan los aportes de Claude Gauvard, quien sostiene que la violencia es globalmente considerada como lícita por los poderes políticos hasta el siglo XIII, por lo menos en el caso del reino de Francia. La pregunta que se hace Gauvard es cómo la monarquía puede condenar a una violencia que en definitiva es alabada por todo el cuerpo social, cómo se puede superar ese signo ambiguo en el ejercicio del poder real. El rey quiere la paz pero comparte los valores del honor que, para esta autora, son comunes al conjunto del cuerpo social y particularmente conciernen a la nobleza. Pero alerta respecto a la caída en un anacronismo: en los siglos XIII-XIV la idea de soberanía no implica que el rey tenga que ejercer el monopolio del ejercicio legítimo de la fuerza. El poder justiciero del rey se expresa a través de las cartas de remisión; los nobles que cometen homicidio en defensa de su honor deben recurrir ahora a la gracia real para ser eximidos del castigo.

Para Gauvard la rebelión de los nobles y sobre todo la revuelta de los no nobles son formas de violencia mucho más peligrosas para el poder real que un homicidio en defensa del honor o incluso que una guerra privada, pues parece considerar que estas últimas manifestaciones de violencia entran en la misma lógica que permite la lenta

Medievalista online № 18| Julho - Dezembro 2015 @ IEM - Instituto de Estudos Medievais 11 www2.fcsh.unl.pt/iem/medievalista 
construcción del poder justiciero del rey, mientras que las nombradas en primer término tienden a socavar sus fundamentos ${ }^{27}$.

Hacia fines de la Edad Media, la violencia por encargo es condenada, mientras que la legítima defensa -la venganza- es considerada una violencia lícita. Este enfrentamiento cara a cara se retrae poco a poco al horizonte de un duelo en el centro del cual se encuentra el cuerpo, al que la violencia atenta noblemente. Descartando los asesinos a sueldo de este campo permitido, el discurso de los jueces desemboca en una puesta en orden de los actos vindicatorios. La muerte por encargo puede entonces ser calificada de asesinato $^{28}$.

En las conclusiones de un congreso sobre la regulación de los conflictos en la Edad Media $^{29}$, la autora sostiene que se puede seguir un hilo continuo durante los mil años que cubren el período, lo que obliga a no mantener las rupturas tradicionales, por ejemplo la del "descubrimiento" del derecho romano, que separaría un tiempo de la justicia antes y después del siglo XIII, o la de la "ruptura” del año mil. Si existe efectivamente una evolución en la historia de los modos de resolución de conflictos, ésta consiste en una ampliación de la gama de resoluciones más que en su transformación de un modo en otro. Esto permite elegir entre jueces o árbitros, incluso entre varios jueces, o aun pasar de uno a otro modo de resolución, lo que lleva a una sociedad donde los medios de resolución de los conflictos son tan numerosos que permiten reparar el tejido desgarrado y asegurar a la vez la estabilidad y la reproducción del cuerpo social.

En estas condiciones, indica la autora, todas las tesis que hablan de un desorden visceral, tanto el de los siglos X-XII como el del fin de la Edad Media, caen. El Estado bajomedieval no es débil porque los modos de resolución de conflictos parezcan anárquicos. El Estado mismo está sumergido en la existencia de relaciones violentas de

\footnotetext{
${ }^{27}$ GAUVARD, Claude - "Violence licite et violence illicite dans le royaume de France à la fin du Moyen Âge”. in Memoria y Civilización. Universidad de Navarra. 2 (1999), pp. 87-115.

${ }^{28}$ GAUVARD, Claude - "La violence commanditée. La criminalisation des "tueurs à gages" aux derniers siècles du Moyen Âge”. in Annales Histoire, Sciences Sociales. 5 (2007), pp. 1005-1029.

${ }^{29}$ GAUVARD, Claude - "Conclusion". in Le règlement des conflits au Moyen Age. Actes du XXXIè Congrès de la SHMESP (Angers, 2000). Paris: Publications de la Sorbonne, 2001, pp. 369-391.
} 
las que se nutre, y el conjunto del período se inscribe en un sistema vindicatorio constante.

La sociedad medieval no está entonces abrumada por la violencia en el sentido de que aquella no se continúa en un ciclo ilimitado y anárquico, sino que está inmersa en una violencia que le es inherente. Es ella la que le permite ser y aparecer ante los ojos de los otros, individualmente y colectivamente, la que le permite la clasificación social y funda las jerarquías. La violencia permanece como un valor compartido y respetado por todos a pesar de las condenas de la que puede ser objeto y este valor le confiere su orden y su función en el seno del cuerpo social. Pero existe una buena y una mala violencia, la que se conforma a las reglas más o menos tácitas y la que se desliza hacia lo ilícito y es, por lo tanto, condenable. Desde la Paz de Dios y de manera más estricta a fines de la Edad Media, estas distinciones se aplican incluso a los hombres de armas.

Gauvard sostiene que el espíritu procedimental es un medio de resistencia, ciertamente contra el Estado, pero también y sobre todo contra los otros. En la mirada de los otros está la violencia más radical, aquella que conduce a asesinar o a saquear para vengarse o simplemente para permanecer. Allí está también la denuncia, que conduce a la expulsión del indeseable.

Al estudiar a "la Francia sin Estado" de los siglos XI y XII, Patrick Geary sostiene que, como sucede en la mayoría de las sociedades -incluidas las sociedades occidentales actuales- el conflicto juega un papel esencial y generalmente constructivo en la vida cotidiana $^{30}$. El autor ve a la violencia como un agente regulador, cuya función sería estabilizar la sociedad. Cada conflicto pone en cuestión la jerarquía y los lazos sociales existentes, que deben ser reafirmados o rotos. Más que como acontecimientos, analiza a los conflictos como estructuras que se prolongan frecuentemente a través de varias generaciones.

Geary advierte que la falta de un tribunal público reconocido no significa que la sociedad viva en la anarquía. La primera manera de tratar un diferendo es la guerra,

\footnotetext{
${ }^{30}$ GEARY, Patrick - "Vivre en conflit dans une France sans État: typologie des mécanismes de règlement des conflits (1050-1200)”. in Annales E.S.C. 5 (1986), pp. 1107-1133.
}

Medievalista online $N^{\circ} 18$ | Julho - Dezembro 2015 ๑ IEM - Instituto de Estudos Medievais 13 www2.fcsh.unl.pt/iem/medievalista 
pero también se pueden llevar adelante negociaciones y arbitrajes a cargo de determinadas figuras que van construyendo poder por medio de la función de justicia. Así, el autor considera que los tribunales privados, de jurisdicción muy restringida, servían más como fuente de recursos y de control social para los poderosos que como instituciones destinadas a instaurar el orden público. En los siglos XIII-XIV reaparecen los tribunales públicos, impuestos por los poderosos -condes, reyes, obispos, papas-, para extender su autoridad coercitiva no sólo sobre sus siervos y esclavos, como ya lo venían haciendo, sino también sobre los guerreros libres, los nobles y el clero.

Geary toma como estudio de caso un conflicto que se desarrolla en la región francesa de Chorges en el siglo XI, durante el cual los monjes emprenden una guerra ritual contra la comunidad laica: no le otorgan los sacramentos, practican ritos de excomunión -la que es lanzada previamente por el arzobispo-, maldiciones litúrgicas, mortificaciones públicas, etc. Para los clérigos, la conducta equivocada de los laicos que los enfrentan subvierte las relaciones estructurales de la sociedad, y las prácticas anteriormente enumeradas sirven para hacer público el mal realizado y para reafirmar esas relaciones. Los monjes se esfuerzan por obligar a la mayor parte de la sociedad a tomar posición en el conflicto.

El objetivo del clamor y de la liturgia en general es el de influir en los fieles a fin de que tomen partido: la excomunión deviene en un exilio del seno de la comunidad. Bajo la amenaza de sufrir la misma pena, nadie debe alimentar o asistir en ninguna forma al excomulgado, ni hablarle si no es para instarle a arrepentirse. En el caso del rito de la humillación, la Iglesia se cierra al mundo laico, privándole del acceso a lo divino hasta el restablecimiento de la situación.

Los ritos cobran particular importancia en ciertos momentos críticos de la vida de los hombres: se intenta revertir la excomunión a la hora de la muerte, se busca la bendición de la Iglesia indispensable para asegurar una unión matrimonial legítima y fecunda, etc. En esos momentos claves, la Iglesia puede ejercer una presión particularmente fuerte sobre los opositores. Estas presiones, que se aplican tanto sobre los individuos como sobre la comunidad, no tienen como objeto destruir a los enemigos de la Iglesia, sino incitarlos a negociar un acuerdo. Los ritos de reconciliación que siguen a las negociaciones exitosas son también públicos.

Medievalista online № 18| Julho - Dezembro 2015 @ IEM - Instituto de Estudos Medievais 14 www2.fcsh.unl.pt/iem/medievalista 
En un estado de la cuestión sobre la relación entre violencia, norma y regulación social en la historiografía francesa ${ }^{31}$, Laure Verdon indica que la tesis -sostenida entre los medievalistas principalmente por Patrick Geary- que ve a la violencia como un agente regulador, cuya función sería estabilizar la sociedad, se encuentra actualmente fuertemente matizada, incluso cuestionada, ya que muchos historiadores insisten sobre todo en la presencia de elementos jurídicos sólidos, provenientes del derecho escrito romano y canónico o de la costumbre, en los procedimientos de regulación de los conflictos medievales. El Estado, en el sentido del conjunto de los procedimientos que llevan a ordenar la sociedad bajo la autoridad pública, no sería entonces un elemento exógeno llegado progresivamente, a partir del siglo XII, para reestructurar una sociedad en disolución, sino que representaría acabadamente el producto de un proceso jurídico y político arribado al estado de su terminación.

Por otra parte, en el mismo artículo Verdon aplica a la Edad Media la distinción entre violencia "horizontal” y violencia “vertical”, de origen antropológico. La violencia "horizontal”, entre iguales, concierne a la de los aristócratas entre sí o frente a los establecimientos eclesiásticos contra los cuales están en conflicto. Este tipo de violencia, que consiste en afirmar un derecho que se considera legítimo, es frecuentemente la consecuencia de la reivindicación de este mismo poder por otra persona. Se relaciona así con la cuestión de los derechos de los parientes y con los conflictos que se suscitan, por ejemplo, cuando la familia del que ha donado un bien a la Iglesia pretende mantener el derecho sobre ese bien. Existe también una violencia “vertical”, que se ejerce en el marco del señorío, en la relación entre dominadores y dominados. Puede tratarse de una violencia física directa -frecuentemente considerada como la marca por excelencia de la coerción-, puede consistir en una presión fiscal demasiado elevada o incluso en el mantenimiento de un estatus considerado humillante, como la servidumbre. La violencia puede también darse en el otro sentido y convertir al señor en víctima volviendo contra él al conjunto de sus dependientes. Las fuentes son en este aspecto muy poco numerosas pero no totalmente inexistentes. Verdon hace referencia, para Flandes en los siglos XI-XII, a un conjunto de siete crónicas y textos

31 VERDON, Laure - "Violence, norme et régulation sociales au Moyen Âge. Essai de bilan historiographique”, Rives méditerranéennes, 2011, Nº 40, pp. 11-25.

Medievalista online № 18 | Julho - Dezembro 2015 @ IEM - Instituto de Estudos Medievais 15 www2.fcsh.unl.pt/iem/medievalista 
hagiográficos que construyen el relato del asesinato de un señor y subrayan todos los roles posiblemente atribuidos a la violencia en tanto modo de regulación social ${ }^{32}$. La puesta en escena de la violencia, en particular, invierte aquí el esquema narrativo de la cólera que conduce a la venganza, normalmente asociada al comportamiento señorial. El desarrollo de la acción ordenada en una serie de secuencias sucesivas -conjuración, momento de pasaje al acto, modo de ejecución, represión- subraya que el resorte de la violencia es la búsqueda de la venganza perseguida a dos niveles: el de la comunidad que, en situación de crisis, no cuenta con otros medios, en esta época de establecimiento de las estructuras del señorío, que prender directamente al señor o a sus agentes; el de Dios que, autorizando el cumplimiento del asesinato, vuelve manifiesta la inmanencia de la justicia divina. Por otra parte, en la mayoría de los relatos el señor era conocido por sus excesos, los que iban asociados al desprecio de los mandamientos divinos ${ }^{33}$.

Respecto a los historiadores anglosajones, un punto de partida en relación a la vinculación entre violencia y dominación se puede encontrar en un trabajo reciente de Peter Linebaugh, que tiene entre sus objetivos recordar la estrecha relación entre los derechos que se podrían caracterizar primordialmente como civiles y políticos contenidos en la Carta Magna de 1215, y los de carácter económico y social contemplados en su contemporánea Gran Carta del Bosque ${ }^{34}$. El autor indica que al rey Juan se le impusieron dos cartas $^{35}$ : la denominada Carta Magna establecía, en su mayor parte, los derechos políticos y jurídicos, mientras que la Gran Carta del Bosque, posteriormente relegada, se ocupaba de los derechos relacionados con la supervivencia económica. El mensaje que lee Linebaugh al vincular ambas Cartas, y que transforma en el mensaje de su libro, es que los derechos políticos y legales sólo pueden existir

\footnotetext{
32 JACOB, Robert - “La meurtre du seigneur dans la societé féodale: la mémorie, le rite, la fonction”. in Annales E.S.C. 45 (1990), pp. 247-263.

33 VERDON, Laure - "Violence, norme et régulation sociales au Moyen Âge. Essai de bilan historiographique”. in Rives méditerranéennes. 40 (2011), pp. 11-25.

${ }^{34}$ LINEBAUGH, Peter - El Manifiesto de la Carta Magna. Comunes y libertades para el pueblo. Madrid: Traficantes de Sueños, 2013.

${ }^{35}$ Es de hacer notar que la Gran Carta del Bosque es finalmente dada por su hijo, Enrique III, en el año 1217, tal como figura en las versiones inglesa y castellana que aparecen en LINEBAUGH, Peter - El Manifiesto de la Carta Magna. Comunes y libertades para el Pueblo. Madrid: Traficantes de Sueños, 2013, pp. 298-302 y 317-322.
}

Medievalista online № 18| Julho - Dezembro 2015 ๑ IEM - Instituto de Estudos Medievais 16 www2.fcsh.unl.pt/iem/medievalista 
sobre una base económica ${ }^{36}$. Si se tiene presente sus condiciones de producción, indica Linebaugh, "La Carta Magna era un tratado entre fuerzas contendientes en una guerra civil”37. El autor emprende un extenso recorrido cronológico y geográfico analizando la indiscutida herencia que han dejado ambos documentos.

En este punto se deben introducir términos polisémicos y de gran carga social, política, simbólica, como son las palabras “común” y “comunidad”, trabajadas -entre muchos otros- por John Watts, en relación a la Inglaterra bajomedieval ${ }^{38}$. Entre los diferentes usos, el autor presenta a los comunes como grupo social y como una de las Cámaras del Parlamento, como todo el pueblo (popolo) o como la parte más baja (plebs), como colectividad política o como grupo social. “Comunes”, recuerda Watts, fue una de las nociones principales de la vida política inglesa entre los siglos XIV y XVI. Sostiene que es una palabra que, en el siglo XIV, primariamente denotaba a la comunidad política, y en el curso del siglo XV, llegó a significar gradualmente algo muy cercano a lo que se denomina "clase baja”. Concluye que evoca tanto a la idea de comunidad política como a la de la masa de la población, y lo más importante, las fusiona. Esta fusión ayuda a explicar puntos claves de la Baja Edad Media inglesa: la relativa apertura de la sociedad política -sin olvidar la largamente retrasada represión de la servidumbre a fines del siglo XIV-; su convulsividad, particularmente en este período; y la frecuencia de la acción popular política a gran escala, a lo que el autor denomina “nivel nacional”. Si bien algunos aspectos que relata Watts podrían funcionar en otros lugares, el autor indica que la noción de "los comunes” es quizá más central en la historia de Inglaterra que en cualquier otro reino.

En su estudio sobre los "manorial custumals" ingleses, donde los señores registran las costumbres y los servicios que les deben sus arrendatarios, Jean Birrel muestra diversas formas de lucha de los arrendatarios campesinos contra los intentos de los señores terratenientes de incrementar rentas y servicios en el siglo XIII, que irían desde rechazar

${ }^{36}$ LINEBAUGH, Peter - El Manifiesto de la Carta Magna. Comunes y libertades para el pueblo. Madrid: Traficantes de Sueños, 2013, p. 27.

${ }^{37}$ LINEBAUGH, Peter - El Manifiesto de la Carta Magna. Comunes y libertades para el Pueblo. Madrid: Traficantes de Sueños, 2013, p. 63.

${ }^{38}$ WATTS, John - "Popular Voices in England's Wars of the Roses, c. 1445-c. 1485”. in University of Oxford, History Working Paper. ${ }^{\circ}$ XIV (2013). 
servicios de trabajo hasta litigar en los tribunales regios. Sostiene así que los campesinos nunca funcionaron como recipientes vacíos ${ }^{39}$.

Entre los autores de habla hispana, Isabel Alfonso Antón aborda en distintas oportunidades la problemática de la violencia, en especial en su relación con el poder.

Sostiene la autora que

... la violencia no puede considerarse simplemente como una práctica arbitraria y predatoria para imponerse sobre los campesinos [...] sino más bien una acción política en el proceso de competición interseñorial por ese dominio. Competición que [...] se jugaba violenta y legalmente, pero no de forma necesariamente opuesta sino a menudo estrechamente imbricada ${ }^{40}$.

Alfonso Antón destaca como "una de las más fecundas líneas de renovación de la historia política tradicional” a aquella que "se centra en el análisis de los procesos, variados, complejos y conflictivos, por los cuales se genera, mantiene y reproduce el poder y en el estudio de sus medios de control y distribución”, y se propone identificar las formas y modos, tanto materiales como simbólicos, por los que se legitima la lucha política en las sociedades medievales, enfatizando a su vez la investigación comparada Planea también la relación entre formas de violencia y existencia o no de estructuras políticas organizadas. La opinión más generalizada, indica Alfonso Antón, parece considerar que determinadas formas de violencia sólo se habrían dado en sociedades donde el poder no estaba políticamente institucionalizado, o era muy débil. La función de estructurador social que algunos antropólogos han atribuido a estos conflictos en sociedades sin una organización política formalizada, o menos formalizada que la occidental actual, junto a una noción restringida de la violencia como un mecanismo utilizado en defensa propia, entendido como intercambios sin fin de violencias vindicatorias (el feud o la venganza de sangre), no respondería a la información que predomina en la documentación medieval, lo que ha impulsado otros tipos de estudios ${ }^{41}$.

${ }^{39}$ BIRRELL, Jean - “Manorial Custumals Reconsidered”. in Past and Present. 224 (2014), pp. 3-37.

${ }^{40}$ ALFONSO ANTÓN, Isabel - "Campesinado y Derecho: la vía legal de su lucha (Castilla y León siglos X-XIII)”. in Noticiario de Historia Agraria. 13 (1997), pp. 15-31.

41 ALFONSO ANTÓN, Isabel - “Los nombres de la violencia y el control de su legitimación”. in Hispania: Revista Española de Historia. Vol. 61, n 208 (2001), pp. 691-706. 
En un trabajo sobre la comunidad campesina gallega bajomedieval ${ }^{42}$, la historiadora introduce precisiones sobre tres conceptos, a los que considera también hipótesis de trabajo. Estos son: campesino, comunidad y dominación. En referencia al primer término, la autora indica el sinsentido de la queja -tantas veces reiterada por los investigadores- sobre el hecho de que la palabra de los dominados llega al presente mediada por la de los dominadores. Esto demuestra que hay que situar la noción de “campesino" en el interior de las relaciones de dominación vigentes en el momento de producción de la fuente. En relación al segundo término, comunidad, Alfonso Antón indica que, a pesar de su centralidad en la historia rural de la Europa occidental continúa siendo un concepto ambiguo, que expresa diversas interrelaciones sociales que implican propiedad, tenencia, parentesco, clientela, vecindad, amistad, etc,

En cuanto al tercer concepto, dominación, lo acota a una suerte de

sinónimo de jurisdicción, ejercicio de un poder público de concesión real por determinadas
instituciones y familias que las faculta para administrar justicia, percibir determinados
impuestos en su provecho, dictar normas o estatutos locales, exigir la prestación de
servicios militares, establecer algunos monopolios... y que suele ser asociada con el ban
francés [...] Se acepta en general como el medio que permite el control sobre el
campesinado, sin embargo, es un concepto susceptible de un discurso contradictorio.

Esto se debe, fundamentalmente, a lo que podríamos calificar como "polaridad” del término, que se relaciona, en un extremo, con el proceso de extracción de parte de la producción campesina, y por el otro, el ofrecimiento de protección y defensa que legitimaría esa relación de poder. Así, concluye la autora, la dominación "es entendida como un concepto dialéctico que combina poder y obediencia”.

En un trabajo más reciente ${ }^{43}$, Alfonso Antón indica algunas líneas de investigación a seguir, entre las que se cuenta el estudio de la concepción pedagógica y terapéutica de la violencia, que permitiría inculcar conductas consideradas apropiadas. Otro aspecto es la concepción del cuerpo como lugar fundamental para ejercer la violencia, viendo al maltrato y al respeto como las dos caras de una misma concepción del orden social. En este punto, la autora llama la atención sobre el significado simbólico de diferentes

\footnotetext{
${ }^{42}$ ALFONSO ANTÓN, Isabel - "La comunidad campesina". in AA.VV. - Poder monástico y grupos domésticos en la Galicia foral (siglos XIII- XV). La casa. La comunidad. Madrid: Consejo Superior de Investigaciones Científicas, 1990, pp. 303-372.

${ }^{43}$ ALFONSO ANTÓN, Isabel - "El Cuerpo del delito y la violencia ejemplar". in FIERRO, M. y GARCÍA FITZ, F. (Eds.) - Cuerpo derrotado: cómo trataban musulmanes y cristianos a los enemigos vencidos (Península Ibérica, ss. VIII-XIII). Madrid: CSIC, 2008, pp. 397-431.
}

Medievalista online № 18| Julho - Dezembro 2015 ๑ IEM - Instituto de Estudos Medievais 19 www2.fcsh.unl.pt/iem/medievalista 
prácticas de la violencia sobre los cuerpos. También destaca el funcionamiento de normas de control social mediante la manipulación consciente de algunas emociones, entre ellas el miedo o la vergüenza, que aparecen en la documentación medieval como elementos positivos a emplear para lograr comportamientos adecuados. Finalmente, hace referencia a la necesidad de analizar los modos en que se construye la alteridad de los enemigos.

Corina Luchía estudia las disputas por el usufructo de los términos colectivos en los concejos de realengo castellanos en la Baja Edad Media ${ }^{44}$. Ante las múltiples formas de estos enfrentamientos, analiza la noción de estrategia presente en las prácticas campesinas, que van desde la negociación hasta la acción directa. Parte de la hipótesis de que, en el contexto de reproducción contradictoria del régimen feudal, los conflictos por la tierra expresan el nivel estructural de la lucha de clases, ya que la expansión señorial sobre el espacio dificulta la reproducción de la base productiva del feudalismo. Las luchas recorren los caminos de la mediación, la violencia y el consenso, siendo la vía judicial la predominante, presentándonse los tribunales como "escenario de las luchas por el poder, entre los dominantes, y contra el poder, entre los dominados”.

En la dinámica social y política del régimen feudal castellano bajomedieval, las luchas por las tierras concejiles de realengo remiten a las formas en que el poder se estructura en el nivel local. Así, el campesinado emplea en forma creativa la legalidad regia, estableciéndose un vínculo entre sus intereses y los del realengo. Pero cuando la ofensiva privatizadora de los señores altera las prácticas productivas del campesinado, sostiene Luchía, “el conflicto se activa ya no como respuesta puntual ante una acción abusiva, sino como oposición al despliegue del régimen social”.

En un trabajo reciente, Carlos Astarita analiza formas de lucha social en el feudalismo, teniendo presente su dimensión simbólica y la categoría de estatus ${ }^{45}$. A través de un minucioso análisis de la documentación seleccionada, busca captar conductas conflictivas deteniéndose en escenarios medievales diversos, tales como un motín

\footnotetext{
${ }^{44}$ LUCHÍA, Corina - "Política y violencia en torno a las luchas por la propiedad comunal en la Baja Edad Media castellana”. in Anales de Historia Antigua, Medieval y Moderna. 43 (2011), pp. 127-158.

${ }^{45}$ ASTARITA, Carlos - "Conflictos sociales, estatus y dimensión simbólica durante la Edad Media”. in Cuadernos de Historia de España. º LXXXV-LXXXVI (2012), pp. 68-83.
} 
acaecido en Santiago de Compostela a comienzos del siglo XII, la rebelión de Sahagún de la misma época, la revolución inglesa de 1381, las Germanías de Valencia de 15191523, etc.

Astarita recuerda que las causas de estas protestas eran políticas, institucionales, económicas y sociales. Los dominados se enfrentan contra el estatus, representado y a su vez encarnado en los símbolos. Actúa en esos momentos un lenguaje simbólico impuesto por los grupos dominantes, al que responde un contralenguaje también simbólico y racional elaborado por los dominados, en una inversión de valores. En contra de la tesis de un supuesto equilibrio homeóstatico, Astarita asevera que la disrupción acaecida por estas luchas podía traducirse en cambios reales.

\section{2 Violencia, poder y religión}

En su estudio sobre la relación entre el movimiento de disidencia religiosa provocado por John Wyclif hacia 1370 y el levantamiento campesino inglés de 1381, Steven Justice analiza en distintas fuentes las prácticas de los rebeldes, y llama la atención sobre la irreflexiva asociación entre revuelta y herejía. La creencia normativa religiosa podría alentar y justificar la rebelión tanto como la sumisión, podría proveer tanto a los rebeldes como a sus señores de recursos de auto-explicación y auto-justificación. Concluye indicando que la creencia y el sentimiento religioso podían ser conflictivos, variados y con múltiples significaciones ${ }^{46}$.

Desde el campo historiográfico francés, Dominique Barthelemy estudia la relación entre violencia, poder y religión. Su hipótesis inicial es probar la eficacia de la función de la violencia caballeresca unida al poder sagrado. Se detiene en la faida, "venganza codificada y limitada” ${ }^{47}$, que se correspondería con la moderación del sistema feudal, en permanente equilibrio entre la guerra y la paz, en un intento de perpetuar la estructura social existente. Como Georges Duby, no encuentra en la caballería "una violencia

\footnotetext{
46 JUSTICE, Steven - "Religious Dissent, Social Revolt, Ideology”. in Past \& Present. 2007, Supplement 2, pp. 205-216.

47 BARTHÉLEMY, Dominique - Caballeros y milagros. Violencia y sacralidad en la sociedad feudal. Granada: Universitat de València, Universidad de Granada, 2006, pp. 12-14.
} 
desatada” y, en los ejemplos que recoge sobre San Benito y Santa Fe de Conques, la relaciona con la sacralidad, ya que se cree firmemente que las oraciones, la liturgia, las reliquias, defienden contra la muerte. Los mismos santos matan a los caballeros que persiguen a sus siervos, en los profusamente documentados “milagros de venganza”48.

El historiador belga Steven Vanderputten señala que, desde comienzos de 1980, los estudiosos han sostenido que rituales, gestos, expresiones faciales, y otros medios verbales y no verbales de comunicación funcionaron como potentes transmisores de valores en las políticas medievales. Promulgados los principios elementales de la organización humana, tales como autoridad, jerarquía y diferenciación social, estas formas de conducta ayudaron a establecer un habitus o comprensión compartida de cómo debe ser ejercido el poder. Vanderputten evalúa el significado de estos debates para el estudio de la conducta pública como un vehículo de movilidad social, adoptando una mirada más cercana a cierto número de disputas sobre tenencia de la tierra entre monjes benedictinos y la élite inferior laica en el condado de Flandes durante el siglo XI y comienzos del XII. Estudia la función del conflicto, tomando como ejemplo un episodio, la castración de Albericus, donde encuentra lo que denomina una contraviolencia controlada. Hay muchas instancias documentadas donde aparecen señores laicos con sus partidarios destruyendo cosechas y activos económicos cruciales (tales como molinos y granjas), tomando rehenes y perturbando en forma generalizada la vida en las comunidades rurales. Las fuentes son inequívocas sobre el propósito de la violencia simbólica ejercida por las comunidades monásticas, pero a menudo niegan la posibilidad de que sus enemigos se comportaron de maneras que puedan ser decodificadas como significativas.

Aunque marcada por un alto grado de violencia, la sociedad flamenca de los estudios de caso considerados aquí tiene interacciones mucho más complejas que lo que el discurso monástico contemporáneo llevaría a creer. Muchas situaciones conflictivas fueron manejadas por medio de performances públicas basadas en un discurso en el cual el ejercicio del poder estaba legitimado por la implementación de un sistema compartido de reglas diseñadas para prevenir la violencia descontrolada. Que la promulgación de

\footnotetext{
${ }^{48}$ BARTHÉLEMY, Dominique - Caballeros y milagros. Violencia y sacralidad en la sociedad feudal. Granada: Universitat de València, Universidad de Granada, 2006, pp. 151-152.
}

Medievalista online № 18| Julho - Dezembro 2015 ๑ IEM - Instituto de Estudos Medievais 22 www2.fcsh.unl.pt/iem/medievalista 
este sistema estuviera asociada con el ejercicio del poder -sostiene Vanderputtenaseguraba que la sociedad pudiera organizarse en ausencia de un fuerte sistema institucional de gobierno, pero también generaba considerables tensiones. Los monjes usaron diversas formas de violencia simbólica para tomar represalias contra los “ataques” de sus adversarios mientras intentaban contener la fragmentación del poder laico por estancamiento o incluso evitando el proceso de negociación. Así, la violencia "significativa” emerge de las fuentes altomedievales como la prerrogativa de una élite establecida tratando aparentemente de mantener un balance de poder con sus propios círculos. Sin embargo, a veces tenía también una función política cuando las fronteras sociales se desvanecían ${ }^{49}$.

\section{3 Violencia y emociones}

Entre los historiadores anglosajones, Barbara Rosenwein propone un modelo interpretativo centrado en el estudio de las que denomina “comunidades emocionales”50. Crítica al modelo de Johan Huizinga y Norbert Elias que considera a la Edad Media como la infancia de Europa. Sostiene que la mayoría de los modernistas han aceptado sin reservas este carácter "infantil” de la Edad Media, y si los medievalistas lo han atemperado empujando la fecha del "proceso de civilización” a los siglos XI y XII incluso al X- muy pocos de entre ellos lo han puesto verdaderamente en cuestión. Las razones de esta actitud se explicarían fácilmente, sostiene Rosenwein. Primero, las fuentes que datan de la Edad Media revelan normas totalmente diferentes a las nuestras, por lo que es fácil calificar a esta época como basta. Por otra parte, la perspectiva de un proceso de civilización concuerda bien con ciertas concepciones concernientes a los afectos vistos como pulsiones irracionales que sólo una auto-disciplina llega a contener. Se comprende así que haya sido necesaria la creación de un Estado absolutista -y de sus formas modernas ulteriores- para prevenir los desbordes. Este modelo de emociones llamado "neumático" o "hidráulico", que permite considerarlas como gases en

\footnotetext{
49 VANDERPUTTEN, Steven - "Monks, Knights, and the Enactment of Competing Social Realities in Eleventh-and Early-Twelfth-Century Flanders”. in Speculum. 84 (2009), pp. 582-612.

${ }^{50}$ ROSENWEIN, Barbara - "Pouvoir et passion. Communautés émotionnelles en Francie au VIIe siècle”. in Annales. Histoire, Sciences Sociales, 2003, n 6, pp. 1271-1292.
} 
expansión o líquidos bajo presión, ha salido de una larga tradición filosófica. Está inscripto en la lengua y traduce bien cómo se experimenta el surgimiento de las emociones. Esta manera de concebir las emociones ha sido suplantada por dos nuevas teorías: la cognitiva y la construccionista; ambas subrayan los casos en los cuales las emociones son reacciones racionales y adaptativas. Algunos medievalistas han comenzado, sobre todo bajo la influencia del construccionismo social, a interrogar la noción misma de "proceso de civilización”. Entre ellos, Rosenwein menciona a Gerd Althoff en Alemania y Stephen White en los Estados Unidos, los cuales, a partir de aproximaciones bastante diferentes, subrayan el carácter funcional de la expresión de los afectos en la Edad Media: aquella, que no sería ni infantil, ni basta, ni elemental, sino más bien orientada hacia la comunicación y la demostración, se revela bien adaptada a un mundo que se apega a la importancia del gesto y del ritual. La autora sostiene que la aproximación cognitivista es valiosa para considerar con una mirada nueva los materiales medievales. Pero la situación no es tan simple, si no los historiadores habrían desde hace tiempo revisado su posición. Toda emoción, en cualquier época que sea, es transmitida de segunda mano, a través de un lenguaje y de gestos convencionales. Conviene estudiar los sentimientos en la Edad Media no sólo como un sistema de signos manifiestos fácilmente comprensibles y codificados sino también, de una manera más general, como parte integrante de múltiples factores de cohesión o de desintegración de las comunidades. De hecho, la gente vivía -y los escritores escribían- en el seno de comunidades emocionales: compartían ciertas convicciones en cuanto a las emociones, valorizando unas en relación a otras e imaginándolas circulando en el seno de grupos determinados. Suponer la existencia de comunidades emocionales sugiere que se pueden encontrar varias en un período dado o sucesivamente.

Rosenwein indica que Norbert Elias establece sin esfuerzo una correspondencia entre la violencia de la época y las emociones incontroladas: según él, afectos, pulsiones y emociones están directamente ligados. Pero existen numerosas formas de violencia y las emociones puestas en acción en el conflicto medieval (elegidas por Elias como ejemplo primero de violencia) no son "refrenadas" sino, al contrario, dominadas y modeladas en conformidad con convenciones perfectamente asimiladas. 
Esta visión se relaciona con la de los historiadores que, como Michael Braddick, trabajan sobre la "política de los gestos”51. El autor parte del concepto de "descripción densa” de Clifford Geertz. Si bien, como indica Braddick, el tipo de análisis etnográfico al que lleva este punto de partida es imposible para casi todos los historiadores, la idea ha sido influyente, sobre todo en la lectura de textos. Braddick sostiene que los gestos pueden ser poderosos medios para comunicar tanto la afirmación y la solidaridad como las disensiones. Los códigos gestuales serían de crucial importancia para un proceso de estructuración por el cual, a través de acciones individuales, se expresan y reproducen relaciones sociales más amplias (estructuras). Por la misma razón, los gestos transgresores o las infracciones de los códigos gestuales, pueden modificar o transformar los patrones de interacción social, dando lugar a un poder con mayor expresión coercitiva o, en su defecto, una dilución del peso cultural y la eficacia de la autoridad. El gesto puede ser así el campo de batalla en el que se libran las visiones divergentes del orden social y político. Estos enfrentamientos pueden ser inconscientes, pero no por ello menos importantes, ni menos reveladores para los historiadores a la hora de hacer amplias suposiciones acerca de las relaciones sociales y su regulación.

Este es un terreno histórico relativamente nuevo. A diferencia de otras formas de acción visible que otorgan significado, los gestos son utilizados junto con las expresiones habladas, y otras veces como complementos, suplementos, sustitutos o alternativas a las mismas. Son los usos enunciativos de la acción visible y son estos usos lo que constituye el dominio del "gesto". Esos usos son deliberativos y, aunque se contraponen al contexto de otra información emitida, constituyen un campo distintivo de la acción comunicativa, que los participantes pueden -o creen que pueden- distinguir de las señales involuntarias. A menudo la riqueza de la comunicación no verbal para el análisis histórico y cultural se encuentra precisamente en esta ambigüedad. Aislar el gesto es una operación valiosa no sólo para comprender su función, sino también para asignarle una red más amplia en la que entender su significado.

\footnotetext{
51 BRADDICK, Michael J. - “Introduction: The Politics of Gesture”. in Past \& Present. 203 (2009), pp.
} 9-35. 
Una política del gesto significa aquí ver cómo las relaciones de poder, las identidades culturales o partidistas y los divergentes intereses sociales se expresaron e impugnaron de forma no verbal. Pero Braddick se pregunta, con razón, hasta dónde pueden ir los historiadores en el análisis de la expresión, la reproducción y la transformación de los órdenes sociales si complementan los análisis habituales con un estudio de la comunicación no verbal, y qué añadiría un estudio de la política del gesto a la comprensión de los problemas históricos, interrogantes que quedarán abiertos.

\section{4 Violencia y lenguaje}

Teniendo al Flandes bajomedieval como escenario, Jan Dumolyn y Jelle Haemers sostienen que el habla subversiva fue uno de los rasgos omnipresentes de la vida política en sus ciudades y constituyó una amenaza continua a la posición de los dominantes, una amenaza que los autores consideran más peligrosa que los estallidos regulares de violencia en los que los especialistas de la política urbana flamenca se han usualmente concentrado ${ }^{52}$. Discutiendo los trabajos ya clásicos de James C. Scott, que presenta a los grupos subalternos operando en oposición a la “ideología hegemónica” y produciendo así “discursos ocultos” que se alternan y oponen a los “discursos públicos”, Dumolyn y Haemers sostienen que los rebeldes flamencos podían construir y expresar sus propios discursos políticos, al mismo tiempo que subvertían parcialmente las ideologías dominantes. Los eventos de habla medievales y temprano-modernos constituyen e incluso definen relaciones políticas entre gobernantes y súbditos. Encontrar huellas de estas expresiones subversivas resulta una tarea ardua pero no imposible, ya que han llegado al presente como fragmentos o citas indirectas en fuentes que se pueden considerar hostiles, que emanan de los grupos dominantes. Existiría una conciencia del peligro potencial que encarnaba el habla popular. La conocida expresión Vox populi, vox Dei -registrada por primera vez en una carta de Alcuino de York- no significa que la voz del hombre común fuera sabia o buena, sino simplemente que era abrumadora y no podía ser ignorada.

\footnotetext{
52 DUMOLYN, Jan and HAEMERS, Jelle - “A Bad Chicken was Brooding': Subversive Speech in Late
} Medieval Flanders”. in Past \& Present. 214 (2012), pp. 45-86. 
Los autores analizan las diversas formas del murmullo, al que califican como un acto colectivo de habla que invariablemente precedería a todo levantamiento pre-industrial. Está estrechamente relacionado con el rumor, tema sobre el que presentaremos también reflexiones de otros historiadores.

Por otra parte, la fuerza simbólica de los privilegios o libertades concedidas a las ciudades o guildas eran tanto o más importantes que la precisa interpretación jurídica de sus contenidos. Durante las revueltas podían ser rotos ritualmente en pedazos e incluso comidos por artesanos, así como el príncipe podía “cancelar” un privilegio cortándolo con un cuchillo, tanto era el poder de las palabras, ya sea habladas en voz alta o en forma escrita.

El habla política de las multitudes, concluyen Dumolyn y Haemers, formaba una parte esencial de un repertorio rebelde de violencia simbólica. Sólo cuando fracasaron al intentar influir en las decisiones políticas con palabras las clases populares recurrieron a la violencia física para defender su posición.

En su último libro, Laure Verdon trabaja sobre la Provenza del siglo XIII ${ }^{53}$, haciendo hincapié especialmente en la voz de los dominados que se puede rastrear en las encuestas realizadas por el señor, a las que aquellos estaban obligados a responder, que podía ser empleada como una herramienta de construcción y de afirmación de la autoridad señorial, un instrumento de su legitimación. Pero, aclara Verdon, no es simplemente un instrumento de coerción en manos de los dominadores, sino que la búsqueda de la "verdad” de los hechos -siempre invocada por los que llevaban adelante la investigación- contribuye a producir normas sobre las cuales descansa el juego social. La autora recurre a los trabajos de Joseph Morsel sobre las actas de Weistümer en la Franconia bajomedieval. El interrogatorio también es analizado por Verdon en relación a los rituales judiciales en el ámbito de la dilucidación y la penalización del delito, que llega en ocasiones a la pena capital, la que se aplica en formas muy variadas. En general, la pesquisa aparece como un instrumento normativo que publicita y legitima los resortes de la dominación apoyándose sobre los elementos de la prueba jurídica.

\footnotetext{
${ }^{53}$ VERDON, Laure - La voix des dominés. Communautés et seigneurie en Provence au bas Moyen Âge. Rennes: Presses Universitaires de Rennes, 2013.
}

Medievalista online № 18 | Julho - Dezembro 2015 ๑ IEM - Instituto de Estudos Medievais 27 www2.fcsh.unl.pt/iem/medievalista 
En un artículo en el cual vincula la expresión inglesa gossip -que incluye entre sus traducciones posibles al castellano chisme o murmuración- a la resistencia entre el campesinado medieval, Chris Wickham describe los tipos de conocimiento en los que se basaban los casos en los tribunales ${ }^{54}$. Si había pruebas escritas relevantes, las empleaban con preferencia, y si no, usaban el conocimiento local. En el conocimiento local se distinguía formalmente entre per visum, testigo directo; per auditum, meramente haber escuchado sobre algo, y publica fama, lo que era conocido por todos, conocimiento común. El testigo directo era el único conocimiento totalmente aceptable legalmente, pero la publica fama le estaba cerca, en un segundo lugar; era lo que todos conocían, por lo que era socialmente aceptado como fidedigno. La publica fama estaba básicamente constituida por el chisme.

Wickham se mueve en diferentes escenarios: Italia, Islandia, la Montaillou hecha célebre por Emmanuel Le Roy Ladurie en 1975... Indica que -hasta el momento de publicación de su artículo- el chisme ha sido subestimado y, consecuentemente, poco estudiado. Lo define como el acto de hablar sobre otra gente a sus espaldas, y destaca el artículo pionero de Max Gluckman de 1963. En cuanto a la importancia de su estudio por parte de los historiadores, Wickham rescata principalmente su capacidad de definir un grupo de identidad. Los grupos se construyen a sí mismos por el discurso. Algo de ese discurso es sobre memorias compartidas, o memoria social: el pasado socialmente relevante, que legitima o da significado al presente para el grupo que lo conmemora. El grupo está realmente constituido por el que tiene el derecho de chismear sobre los de afuera, o incluso sobre los ausentes de adentro. Al estudiar la relación del chisme con la resistencia, el autor sostiene que es una guía directa a las líneas de poder. La resistencia exitosa es siempre hablada antes de ser representada. A pesar de que la gente tiende a chismear contra la reputación, no contra la dominación, al final una afectará a la otra: a la gente que haya perdido su reputación se le hará difícil dominar. Como dato a tener en cuenta, Wickham indica que, aunque los principales enemigos y explotadores de los

\footnotetext{
${ }^{54}$ WICKHAM, Chris - “Gossip and Resistance among the Medieval Peasantry”. in Past \& Present. 160 (1998), pp. 3-24.
}

Medievalista online № $18 \mid$ Julho - Dezembro 2015 @ IEM - Instituto de Estudos Medievais 28 www2.fcsh.unl.pt/iem/medievalista 
campesinos en todos los períodos fueron los señores, cuando se los escucha hablar, ellos casi siempre hablan sobre el Estado, o sus equivalentes.

En un trabajo sobre la protesta popular contra Enrique IV de Inglaterra, Simon Walker muestra cómo durante los primeros años de su reinado, grupos o individuos expresaron libremente su insatisfacción con el gobierno del nuevo rey por todo el país ${ }^{55}$. Tales manifestaciones fueron parte de la "infrapolítica" de la Inglaterra bajomedieval, una amplia área de discusión, queja y disenso, que se ubica en algún lugar entre el consentimiento incondicional y la rebelión abierta. El volumen creciente de la crítica refleja un clima de inquietud social generado por un cambio económico rápido y agudizado por la excepcional inestabilidad de las dinastías políticas entre 1397 y 1406. La fuente principal de Walker son las apelaciones de criminales confesos de un crimen capital, los cuales, para evitar la ejecución, informan sistemáticamente sobre muchos de sus cómplices. El autor sostiene que el hecho de que ciertas palabras fueran realmente pronunciadas es usualmente menos importante que el hecho de que se creyera plausible que ellas lo hubieran sido.

El "rumor ricardiano" -la idea de que Ricardo II, el rey depuesto, habría escapado de alguna forma de su cautividad, que estaba todavía vivo, y que podría volver pronto a Inglaterra- era una fuente particularmente fuerte de acusaciones e imputaciones. Satisfacía muy bien los requerimientos de la protesta “infrapolítica”, ocultando la resistencia dentro del idioma del consentimiento a la autoridad legítima. Walker analiza con detenimiento las características específicas y las fases del “rumor ricardiano”, especialmente en los rasgos que lo distinguen de otras manifestaciones relacionadas con el topos del rey perdido o el rey dormido, cuyo retorno es esperado por el pueblo. Las diferentes fases de desarrollo del rumor sobre el regreso del rey depuesto tienen su correlato en las muy diversas formas y grados de represión según el momento político, que van desde castigos severísimos - entre ellos amputaciones de lengua y de manos, e incluso pena de muerte- hasta una actitud casi tolerante. El perdón, indica Walker, fue preferido al castigo como medio de clausura. Aceptando un perdón, el ofensor reconocía

\footnotetext{
55 WALKER, Simon - "Rumour, Sedition and Popular Protest in the Reign of Henry IV". in Past \&
} Present. 166 (2000), pp. 31-65.

Medievalista online № $18 \mid$ Julho - Dezembro 2015 @ IEM - Instituto de Estudos Medievais 29 www2.fcsh.unl.pt/iem/medievalista 
que un crimen había sido efectivamente cometido, y reconocía a su vez la autoridad el rey para ejercer su prerrogativa de gracia. La aspiración general del gobierno de Enrique IV era la contención, no la erradicación, del rumor ricardiano. Ambas partes ganaban algo con esto. La ambigüedad es una de las más grandes fortalezas del rumor, y permitió el avance de la crítica dañina a Enrique IV para luego, cuando fuera necesario, repudiarla.

Para Walker, la evidencia sugiere que podría ser inapropiado bosquejar una distinción demasiado tajante entre las actitudes y preocupaciones de los gobernantes y gobernados en la Inglaterra bajomedieval, ya que existiría un conjunto común de creencias y actitudes, aunque apropiado e interpretado de acuerdo a las circunstancias y predilecciones individuales.

Entre los autores en lengua hispana, son pertinentes las reflexiones de José Manuel Nieto Soria sobre la palabra como un instrumento de lucha en la Castilla bajomedieval $^{56}$. El autor comienza con una distinción entre palabra y violencia con la que aquí no se concuerda, al sostener que la lucha política a la que él hace referencia se reduciría a cuatro grandes categorías: la violencia, la retórica, los rituales y la formación de asociaciones políticas, excluyendo la violencia para dedicarse al estudio de las otras tres. Si bien consideramos que la palabra también es portadora de violencia, las apreciaciones de Nieto Soria pueden ser de gran utilidad para entender la importancia del discurso. El autor indica que la palabra juega un rol decisivo en la confrontación, ejerciendo diferentes funciones, cada una con su propio modelo retórico. Así, sirve para legitimar, reivindicar, difundir o incluso perpetuar algo. Para ello, hace referencia a principios superiores - tales como la defensa del reino, de la corona, del bien comúncon lo que su enunciador logra confiscar los intereses del conjunto de la comunidad política para la consecución de sus propios intereses. Nieto Soria presenta también aquí, al tratar la legitimación, al discurso deslegitimador, indicando que en este período se relaciona fundamentalmente con las teorías sobre la tiranía, que en parte desarrolla. Vincula los argumentos de los Trastámara a las reflexiones políticas del humanismo

\footnotetext{
${ }^{56}$ NIETO SORIA, José María - "La parole: un instrument de la lutte politique dans la Castille de la fin du Moyen Âge”. in Revue historique. 632 (2004), pp. 707- 725; NIETO SORIA, José María - "El pregón real en la vida política de la Castilla Trastámara”. in Edad Media. Revista de Historia. 13 (2012), pp. 77102.
}

Medievalista online № $18 \mid$ Julho - Dezembro 2015 ๑ IEM - Instituto de Estudos Medievais 30 www2.fcsh.unl.pt/iem/medievalista 
italiano, que abrirían el camino para una justificación plena de la resistencia al tirano de ejercicio, incluso cuando, como en el caso de Pedro I de Castilla, su origen sea legítimo ${ }^{57}$. Pero esta barrera es muy riesgosa de cruzar sin dañar a la monarquía como institución. También subraya el autor que el enfrentamiento político no termina nunca en el momento del fracaso o del triunfo efectivo de una causa, sino que los actores prosiguen la lucha sobre el terreno historiográfico, allí donde pueden actuar sobre el futuro de la memoria histórica y alimentar la memoria colectiva de los hechos pasados.

A modo de cierre de este estado de la cuestión sobre la violencia en la Edad Media, se presentará un artículo de Gadi Algazi sobre lo que el autor denomina el uso social de las guerras privadas en la Alemania bajomedieval ${ }^{58}$. Estas luchas no coordinadas entre señores permitieron su reproducción social en dicho período. En documentación de diverso tipo, Algazi recoge una impactante metáfora: la de la poda de campesinos. La idea de los señores de que los campesinos, al igual que las plantas, a veces deben ser podados, encierra una visión de la violencia como algo positivo, necesario, constructivo, legítimo. Lo que las fuentes muestran, en general, es que los señores consideran que, así como un árbol que creció en exceso necesita ser podado para recobrar su fertilidad y retormar correctamente su crecimiento, gracias a una poda ocasional y a la vez recurrente, los campesinos perderán su arrogancia, su odio a los que los dominan y su individualidad, volviendo a la disciplina y la humildad y ubicándose en el lugar que les corresponde dentro del ordenamiento social. El interés de la metáfora de la poda reside principalmente, según Algazi, en su capacidad de evocar una imagen de violencia productiva. Pero el autor recuerda que la prosperidad campesina no representaba ningún peligro para los propios campesinos, como sí podría hacerlo el crecimiento exuberante de un árbol frutal. La metáfora de la poda, sostiene Algazi, de ningún modo sirvió para obtener el consentimiento campesino a las intervenciones violentas de los señores. Su

57 NIETO SORIA, José Manuel - “La gestación bajomedieval del derecho de resistencia en Castilla: modelos interpretativos”. in Cahiers d'Etudes Hispaniques Médiévales (CEHM). 34 (2011), pp. 13-27.

${ }^{58}$ ALGAZI, Gadi - "Pruning Peasants. Private War and Maintaining the Lords' Peace in Late Medieval Germany”. in COHEN, Esther and JONG, Mayke de (eds.) - Medieval Transformations: Texts, Power and Gifts in Context. Leiden: Brill, 2000, pp. 245-274.

Medievalista online № 18| Julho - Dezembro 2015 @ IEM - Instituto de Estudos Medievais 31 www2.fcsh.unl.pt/iem/medievalista 
rol habría sido reinstalar e intentar perpetuar un orden social, inculcando al dominado un sentido de su lugar en dicho orden.

\section{REFERÊNCIAS BIBLIOGRÁFICAS}

\section{Estudos}

ALFONSO ANTÓN, Isabel - "La comunidad campesina”. in AA.VV. - Poder monástico y grupos domésticos en la Galicia foral (siglos XIII- XV). La casa. La comunidad. Madrid: Consejo Superior de Investigaciones Científicas, 1990, pp. 303372.

ALFONSO ANTÓN, Isabel - “Campesinado y Derecho: la vía legal de su lucha (Castilla y León siglos X-XIII)”. in Noticiario de Historia Agraria. 13 (1997), pp. 1531.

ALFONSO ANTÓN, Isabel - “El Cuerpo del delito y la violencia ejemplar”. in FIERRO, M. y GARCÍA FITZ, F. (Eds.) - Cuerpo derrotado: cómo trataban musulmanes y cristianos a los enemigos vencidos (Península Ibérica, ss. VIII-XIII). Madrid: CSIC, 2008, pp. 397-431.

ALGAZI, Gadi - "Pruning Peasants. Private War and Maintaining the Lords' Peace in Late Medieval Germany”. in COHEN, Esther and JONG, Mayke de (eds.) - Medieval Transformations: Texts, Power and Gifts in Context. Leiden: Brill, 2000, pp. 245-274.

ASTARITA, Carlos - “¿Tuvo conciencia de clase el campesino medieval?”. in Edad Media. Revista de Historia. 13 (2000), pp. 89-113.

ASTARITA, Carlos - "Prácticas del conde y formación del feudalismo. Siglos VII a XI”. in Revista de Historia Medieval. 14 (2003-2006), pp. 21-52.

ASTARITA, Carlos - Del feudalismo al capitalismo. Cambio social y político en Castilla y Europa Occidental, 1250-1520. Granada: Universitat de ValenciaUniversidad de Granada, 2005.

Medievalista online № 18| Julho - Dezembro 2015 @ IEM - Instituto de Estudos Medievais 32 www2.fcsh.unl.pt/iem/medievalista 
ASTARITA, Carlos - "La historia de la transición del feudalismo al capitalismo en el marxismo occidental”. in Anales de Historia Antigua, Medieval y Moderna. 41 (2009), pp. 101-131.

ASTARITA, Carlos - "Conflictos sociales, estatus y dimensión simbólica durante la Edad Media”. in Cuadernos de Historia de España. № LXXXV-LXXXVI (2012), pp. 68-83.

BARTHÉLEMY, Dominique - El año mil y la Paz de Dios. La Iglesia y la sociedad feudal. Granada: Universidad de Granada-Universitat de València, 2005.

BARTHÉLEMY, Dominique - Caballeros y milagros. Violencia y sacralidad en la sociedad feudal. Granada: Universitat de València, Universidad de Granada, 2006.

BIRRELL, Jean - “Manorial Custumals Reconsidered”. in Past and Present. 224 (2014), pp. 3-37.

BONNASSIE, Pierre - Cataluña mil años atrás (siglos $X$-XI). Barcelona: Península, 1978.

BONNASSIE, Pierre - "Del Ródano a Galicia: génesis y modalidades del régimen feudal”. in PASTOR, Reyna (ed.) - Estructuras feudales y feudalismo en el mundo mediterráneo (siglos X-XI). Barcelona: Crítica, 1984, pp. 21-65.

BRADDICK, Michael J. - "Introduction: The Politics of Gesture”. in Past \& Present. 203 (2009), pp. 9-35.

DEVIA, Cecilia - La violencia en la Edad Media: la rebelión irmandiña. Vigo: Editorial Academia del Hispanismo, 2009.

DEVIA, Cecilia - Violencia y dominación en la Baja Edad Media castellana. Buenos Aires: Facultad de Filosofía y Letras, Universidad de Buenos Aires, 2014. Disponible en http://www.filo.uba.ar/contenidos/investigacion/institutos/historiaantiguaymedieval/ libros.htm

DUBY, Georges - Los tres órdenes o lo imaginario del feudalismo. Barcelona: Argot, 1983.

Medievalista online $N^{\circ} 18$ | Julho - Dezembro 2015 ๑ IEM - Instituto de Estudos Medievais 33 www2.fcsh.unl.pt/iem/medievalista 
DUMOLYN, Jan and HAEMERS, Jelle - “A Bad Chicken was Brooding': Subversive Speech in Late Medieval Flanders”. in Past \& Present. 214 (2012), pp. 45-86.

FLORI, Jean - Caballeros y caballería en la Edad Media. Barcelona: Paidós, 2001.

GAUVARD, Claude - "Violence licite et violence illicite dans le royaume de France à la fin du Moyen Âge”. in Memoria y Civilización. Universidad de Navarra. 2 (1999), pp. 87-115.

GAUVARD, Claude - “Conclusion”. in Le règlement des conflits au Moyen Age. Actes du XXXIè Congrès de la SHMESP (Angers, 2000). Paris: Publications de la Sorbonne, 2001, pp. 369-391.

GAUVARD, Claude - "La violence commanditée. La criminalisation des "tueurs à gages” aux derniers siècles du Moyen Âge”. in Annales Histoire, Sciences Sociales. 2007, n 5, pp. 1005-1029.

GEARY, Patrick - "Vivre en conflit dans une France sans État: typologie des mécanismes de règlement des conflits (1050-1200)”. in Annales E.S.C., 1986, nº 5, pp. 1107-1133.

HILTON, Rodney - Siervos liberados. Los movimientos campesinos medievales y el levantamiento inglés de 1381. Madrid: Siglo XXI, 1985.

HILTON, Rodney - “Campesinos medievales: ¿Alguna enseñanza?”. in HILTON, Rodney - Conflicto de clases y crisis del feudalismo. Barcelona: Crítica, 1988, pp. 1124.

IOGNA-PRAT, Dominique - Ordonner et exclure. Cluny et la societé chrétienne face àl’ herésie, au judaïsme et à l' islam. 1000-1150. París: Aubier, 1998.

IRADIEL MURUGARREN, Francisco Paulino - "Estructuras agrarias y modelos de organización industrial precapitalista en Castilla”. in Studia Historia. Historia Medieval. 1 (1983), pp. 87-112.

IRADIEL MURUGARREN, Francisco Paulino - Evolución de la industria textil castellana en los siglos XIII-XVI. Salamanca: Universidad de Salamanca, 1974.

Medievalista online № 18| Julho - Dezembro 2015 ๑ IEM - Instituto de Estudos Medievais 34 www2.fcsh.unl.pt/iem/medievalista 
JACOB, Robert - "La meurtre du seigneur dans la societé féodale: la mémorie, le rite, la fonction”. in Annales E.S.C. 45 (1990), pp. 247-263.

JUSTICE, Steven - “Religious Dissent, Social Revolt, Ideology”. in Past \& Present. 2007, Supplement 2, pp. 205-216.

LINEBAUGH, Peter - El Manifiesto de la Carta Magna. Comunes y libertades para el pueblo. Madrid: Traficantes de Sueños, 2013.

LUCHÍA, Corina - "Política y violencia en torno a las luchas por la propiedad comunal en la Baja Edad Media castellana”. in Anales de Historia Antigua, Medieval y Moderna. 43 (2011), pp. 127-158.

MORETA, Salustiano - Malhechores-feudales. Violencia, antagonismos y alianzas de clases en Castilla, siglos XIII-XIV. Madrid: Cátedra, 1978.

NIETO SORIA, José María - "La parole: un instrument de la lutte politique dans la Castille de la fin du Moyen Âge”. in Revue historique. 632 (2004), pp. 707-725.

NIETO SORIA, José Manuel - "La gestación bajomedieval del derecho de resistencia en Castilla: modelos interpretativos”. in Cahiers d'Etudes Hispaniques Médiévales (CEHM). 34 (2011), pp. 13-27.

NIETO SORIA, José María - "El pregón real en la vida política de la Castilla Trastámara”. in Edad Media. Revista de Historia. 13 (2012), pp. 77-102.

ROSENWEIN, Barbara - "Pouvoir et passion. Communautés émotionnelles en Francie au VIIe siècle”. in Annales. Histoire, Sciences Sociales, 2003, № 6, pp. 1271-1292.

VANDERPUTTEN, Steven - "Monks, Knights, and the Enactment of Competing Social Realities in Eleventh-and Early-Twelfth-Century Flanders”. in Speculum. 84 (2009), pp. 582-612.

VERDON, Laure - "Violence, norme et régulation sociales au Moyen Âge. Essai de bilan historiographique”. in Rives méditerranéennes. 40 (2011), pp. 11-25.

VERDON, Laure - La voix des dominés. Communautés et seigneurie en Provence au bas Moyen Âge. Rennes: Presses Universitaires de Rennes, 2013.

Medievalista online № 18 | Julho - Dezembro 2015 ๑ IEM - Instituto de Estudos Medievais 35 www2.fcsh.unl.pt/iem/medievalista 
WALKER, Simon - "Rumour, Sedition and Popular Protest in the Reign of Henry IV". in Past \& Present. 166 (2000), pp. 31-65.

WATTS, John - "Popular Voices in England's Wars of the Roses, c. 1445-c. 1485”. in University of Oxford, History Working Paper, 2013, N XIV.

WICKHAM, Chris - "Gossip and Resistance among the Medieval Peasantry”. in Past \& Present. 160 (1998), pp. 3-24.

\section{COMO CITAR ESTE ARTIGO}

\section{Referência electrónica:}

DEVIA, Cecilia - “Aproximaciones historiográficas a la violencia en la Edad Media”. Medievalista [Em linha]. № 18 (Julho - Dezembro 2015). [Consultado dd.mm.aaaa]. Disponível em http://www2.fcsh.unl.pt/iem/medievalista/MEDIEVALISTA18/devia1806.html ISSN 1646-740X.

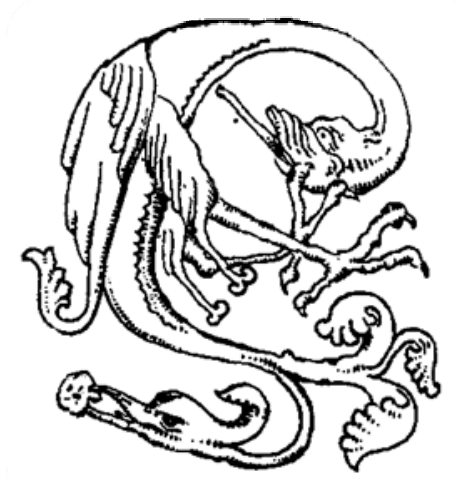

Medievalista online $N^{\circ} 18 \mid$ Julho - Dezembro 2015 ๔ IEM - Instituto de Estudos Medievais 36 www2.fcsh.unl.pt/iem/medievalista 